\title{
Estimates of the aerosol indirect effect over the Baltic Sea region derived from 12 years of MODIS observations
}

\author{
Giulia Saponaro $^{1}$, Pekka Kolmonen ${ }^{1}$, Larisa Sogacheva ${ }^{1}$, Edith Rodriguez ${ }^{1}$, Timo Virtanen ${ }^{1}$, and Gerrit de Leeuw ${ }^{1,2}$ \\ ${ }^{1}$ Finnish Meteorological Institute, Helsinki, 00560, Finland \\ ${ }^{2}$ Department of Physics, University of Helsinki, Helsinki, 00560, Finland
}

Correspondence to: Giulia Saponaro (giulia.saponaro@fmi.fi) and Pekka Kolmonen (pekka.kolmonen@fmi.fi)

Received: 26 July 2016 - Discussion started: 27 October 2016

Revised: 2 February 2017 - Accepted: 13 February 2017 - Published: 28 February 2017

\begin{abstract}
Retrieved from the Moderate Resolution Imaging Spectroradiometer (MODIS) on-board the Aqua satellite, 12 years (2003-2014) of aerosol and cloud properties were used to statistically quantify aerosol-cloud interaction (ACI) over the Baltic Sea region, including the relatively clean Fennoscandia and the more polluted central-eastern Europe. These areas allowed us to study the effects of different aerosol types and concentrations on macro- and microphysical properties of clouds: cloud effective radius (CER), cloud fraction (CF), cloud optical thickness (COT), cloud liquid water path (LWP) and cloud-top height (CTH). Aerosol properties used are aerosol optical depth (AOD), Ångström exponent (AE) and aerosol index (AI). The study was limited to low-level water clouds in the summer.

The vertical distributions of the relationships between cloud properties and aerosols show an effect of aerosols on low-level water clouds. CF, COT, LWP and CTH tend to increase with aerosol loading, indicating changes in the cloud structure, while the effective radius of cloud droplets decreases. The ACI is larger at relatively low cloud-top levels, between 900 and $700 \mathrm{hPa}$. Most of the studied cloud variables were unaffected by the lower-tropospheric stability (LTS), except for the cloud fraction.

The spatial distribution of aerosol and cloud parameters and ACI, here defined as the change in CER as a function of aerosol concentration for a fixed LWP, shows positive and statistically significant ACI over the Baltic Sea and Fennoscandia, with the former having the largest values. Small negative ACI values are observed in central-eastern Europe, suggesting that large aerosol concentrations saturate the ACI.
\end{abstract}

\section{Introduction}

Aerosols and especially their effect on the microphysical properties of clouds are among the key components that influence the Earth's climate. As the magnitude and sign of such effects are not well known, understanding and quantifying the influence of aerosols on cloud properties constitutes a fundamental step towards understanding the mechanisms of anthropogenic climate change (Boucher, 2013).

As aerosols may act as cloud condensation nuclei (CCN), an increase in their number concentration can lead to an increase in the number of cloud droplets in super saturation conditions and a decrease in the cloud droplet radius. The decrease in the droplet effective radius resulting in an increase of the cloud albedo, under the assumption of a constant liquid water path, is known as the Twomey effect (Twomey, 1977). The decrease in droplet size can also impact the precipitation cycle, as the smaller droplets require longer time to grow into precipitating droplet sizes. Additionally, a possible decrease in the precipitation frequency of liquid clouds increases the lifetime of clouds (Albrecht, 1989). These impacts of aerosols are called the first and second indirect effects.

A quantitative evaluation of the effects of aerosols on clouds may be possible mainly in a statistical sense because of the local interactions between meteorological conditions and aerosols (Tao et al., 2012). Satellite-based remote sensing instruments can provide a large data set for statistical analysis from long-term observations of the aerosol indirect effect on a large spatial scale with daily global coverage, complementing localized ground measurements and providing necessary parameters for climate models. 
A common approach in the satellite-based investigation of the first aerosol indirect effect (AIE) is the concept of the aerosol-cloud interaction (ACI), which relates the cloud optical thickness (COT), cloud effective radius (CER) or cloud droplet number concentration (CDNC) to the aerosol loading. The aerosol loading is usually expressed by the aerosol optical depth (AOD) or aerosol index (AI, defined in Sect. 3), which are used as proxies for the CCN concentration.

Many studies describe the interaction between aerosols and clouds through the correlation of the satellite-retrieved aerosol concentration and cloud droplet size on a global or regional scale. Inverse correlations on a global (Bréon et al., 2002; Myhre et al., 2007; Nakajima et al., 2001) and a regional scale (Costantino and Bréon, 2010; Ou et al., 2013) have been found, while Sekiguchi et al. (2003) and Grandey and Stier (2010), applying satellite data on a global scale, found either positive, negative or negligible correlations between the CER and AOD depending on the location of the observations. Jones et al. (2009) emphasized that the ACI should be inferred in aerosols or cloud regimes determined on a regional scale, as the relevance of aerosol type, aerosol concentration and meteorological conditions differs around the world.

Areas located at high latitudes are excluded from most of the studies due to a seasonal limitation of the satellite coverage and a smaller number of observations when compared to the global averages over the year. Lihavainen et al. (2010) compared in situ and satellite measurements to quantify the ACI on low-level clouds over Pallas (Finland), a northern high-latitude site, and concluded that the ACI values derived from ground-based measurements were higher than those obtained from satellite observations. Unlike the in situ instruments, the wavelengths used in the satellite retrievals constrain the detection of fine particles to those larger than about $100 \mathrm{~nm}$, thus making it impossible to account for all CCN. Sporre et al. (2014a, b) combined aerosol measurements from two clean northern high-latitude sites with satellite cloud retrievals and observed that the aerosol number concentration affects the CER, while no impact on the COT was observed. As both studies focused on specific locations, no information was thus provided on a larger scale in the Baltic region. This work investigates whether the first indirect effect can also be observed by means of satellite-derived observations over the Baltic Sea region, a region that offers a northern clean atmospheric background (Fennoscandia) contrasted by a more polluted one (central-eastern Europe).

To determine whether it is possible to observe the response of the properties of low-level liquid clouds to different aerosol loadings in different atmospheric conditions, 12 years of aerosol and cloud properties available from the Moderate Resolution Imaging Spectroradiometer (MODIS) retrievals were investigated on a regional scale.

The satellite retrieval products are introduced in Sect. 2, the approach adopted for the ACI analysis is described in Sect. 3 and the results of the analyses are presented in Sect. 4.

\section{Data}

The area covered in this study is situated at high latitudes $\left(50^{\circ} \mathrm{N}, 10^{\circ} \mathrm{E}, 70^{\circ} \mathrm{N}, 35^{\circ} \mathrm{E}\right)$. At these latitudes the solar zenith angle (SZA) constrains the available satellite data set: a large value of the SZA implies higher uncertainties on the retrieved parameters. Due to the SZA and data coverage constraints, we limit the data set to the summer (June, July, August) observations that were collected by the MODIS instrument between 2003 and 2014. Data are analysed only from the MODIS/Aqua platform that crosses the equator at 13:30 LT (local time), when the clouds are fully developed.

The MODIS Collection 06 Level 3 (C6 L3) product provides cloud and aerosol parameters at daily time resolution and at a regular $1^{\circ} \times 1^{\circ}$ spatial grid. The application of MODIS satellite data to ACI studies is often criticized for the lack of coincidental aerosol and cloud retrievals. Studies such as Avey et al. (2007), Bréon et al. (2002) and Anderson et al. (2003) showed that in the case of daily products at $1^{\circ} \times 1^{\circ}$ resolution it is unnecessary to individually couple the aerosol and cloud measurements. Therefore, in this study aerosol and cloud data are assumed to be co-located.

The MODIS C6 L3 product includes cloud microphysical parameters (CER, COT, cloud liquid water path (LWP)) with statistics (mean, minimum, maximum, standard deviation) determined at three different wavelengths (1.6, 2.1 and $3.7 \mu \mathrm{m}$ ) for each cloud phase (liquid, ice, undetermined) separately.

We filtered the MODIS cloud data according to the following criteria:

- Cloud parameters were only considered in the liquid phase.

- To eliminate possible outliers, retrievals with a standard deviation higher than the mean values were discarded.

- Observations with a mean cloud-top temperature less than $273 \mathrm{~K}$ were eliminated to ensure only warm liquid cloud regimes.

- The multilayer flag was applied to select only singlelayer clouds.

- Transparent-cloudy pixels $(\mathrm{COT}<5)$ were discarded to limit uncertainties (Zhang et al., 2012).

- The CER derived from the $3.7 \mu \mathrm{m}$ wavelength was chosen since it has been shown to be less affected by the subpixel heterogeneity (Zhang et al., 2012).

- To exclude precipitating cases, observations were discarded when the difference between CER at $3.7 \mu \mathrm{m}$ and CER at $2.1 \mu \mathrm{m}$ was greater than $10 \mu \mathrm{m}$ (Zhang et al., 2012).

The science data sets (SDSs) for the atmospheric aerosol information in the MODIS C6 L3 provide the AOD retrieved at several wavelengths and as a product from 
the application of either the "Deep Blue" or "Dark Target" algorithm, or a combination of both retrievals (Levy et al., 2013; Sayer et al., 2014). The SDS "Aerosol_Optical_Depth_Land_Ocean_Mean" is the sole product providing the AOD at $0.55 \mu \mathrm{m}$ globally, while the other aerosol SDSs provide the AOD over land and water separately. As C6 provides the Ångström exponent (AE) over land only, the AOD at the wavelengths of 0.46 and $0.66 \mu \mathrm{m}$ present in both "Aerosol_Optical_Depth_Land_Mean" and "Aerosol_Optical_Depth_Ocean_Mean" were used to derive the AE globally as shown in Sect. 3.

To assess the effect of meteorological conditions on cloud properties, the ECMWF ERA-Interim reanalysis data were applied to derive the lower-tropospheric stability (LTS). Although not a ready-to-use product, the LTS is computed as the difference between the potential temperature at $700 \mathrm{hPa}$ and at the surface (Klein and Hartmann, 1993), describing the magnitude of the inversion strength for the lower troposphere.

\section{Methods}

After selecting the cloud parameters as listed in the previous section, the number of observations were binned for both aerosol and cloud products. From the obtained histograms, $95 \%$ of the most frequent ranges were selected from the total data set by filtering out $2.5 \%$ of data from the extremes. These statistically more robust data sets were used in further analysis.

The product of the AOD, representing the columnintegrated optical extinction of aerosol at a given wavelength, and the derived AE, describing the spectral dependency of the AOD, results in a third aerosol property of interest, the aerosol index (AI). The AI is used as a proxy for the finemode aerosol particles, which have a larger contribution to the $\mathrm{CCN}$ than the coarse-mode particles (Nakajima et al., 2001). MODIS Collection 6 provides the AE only over land. To homogeneously estimate the AI over the Baltic Sea and the surrounding land areas, the AE is evaluated by applying equation

$\mathrm{AE}=-\log \left(\mathrm{AOD}_{\lambda_{1}} / \mathrm{AOD}_{\lambda_{2}}\right) / \log \left(\lambda_{1} / \lambda_{2}\right)$

to the wavelength pair of $\lambda_{1}=0.66 \mu \mathrm{m}$ and $\lambda_{2}=0.46 \mu \mathrm{m}$, which are available both over land and over sea. The C6 MODIS aerosol algorithm does not, however, allow the determination of the $\mathrm{AE}$ for coastal and inland water regions (Levy et al., 2013). This would leave large parts of the Baltic region under investigation in this work out of the analysis (see Fig. 3b and c). For this reason, the ACI was analysed, in addition to the AI, with the AOD. Seasonal mean values of aerosol (AOD, AE, AI) and cloud parameters (CER, cloud fraction (CF), COT) were computed for the period of 20032014.
Aiming to observe how the variation in aerosol conditions influences cloud properties, we adopted the approach of Koren et al. (2005) to analyse the average vertical distribution of the relationships between aerosols and cloud properties. The AOD and AI data sets were firstly sorted in ascending order and successively divided into five equally sampled classes that represent the averages of aerosol conditions for each of the classes. The cloud properties were then divided according to these AI and AOD classes and plotted as functions of cloud-top pressure.

The response of the cloud properties to clean-versuspolluted aerosol conditions was studied spatially. The 25 th and 75th percentiles of the AI and AOD (AI-AOD) were computed for each spatial grid point, the former constituting the upper limit for the AI-AOD values representing low aerosol loadings and the latter representing the lower limit for the AI-AOD values for heavy aerosol loadings. These percentile values were then used to divide cloud parameters for clean and polluted aerosol conditions. The difference between a cloud parameter value in low- and high-aerosol conditions is

$$
\Delta \text { Cloud_X }=\text { Cloud_ } X_{25 \text { th percentile }}-\text { Cloud_ } X_{75 \text { th percentile }} \text {, }
$$

where the considered cloud parameters, Cloud_ $X$, are the CER, cloud-top pressure (CTP), COT, CF and LWP. The subscripts indicate that the cloud parameter is representative for clean atmospheric conditions, Cloud_ $X_{25 \text { th percentile, }}$ or for polluted atmospheric conditions, Cloud_ $X_{75 \text { th percentile. }}$ The difference $(\Delta$ Cloud_ $X$ ) between the cloud parame-

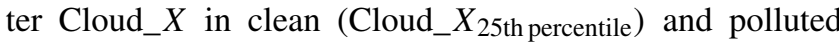

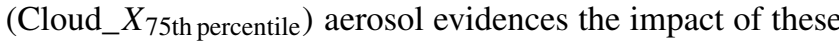
two aerosol cases on the parameter Cloud_ $X$.

Matsui et al. (2006) found that aerosols impact the CER stronger in an unstable environment (low LTS) than in a stable environment (high LTS) where the intensity of the ACI is reduced due to the dynamical suppression of the growth of cloud droplets. Following this result, we also compared cloud microphysical properties with both the AI-AOD and the LTS.

The area of this study was divided into three subregions as presented in Fig. 1: Area 1 covers the Baltic Sea, while Area 2 and Area 3 include only land pixels over Fennoscandia and central-eastern Europe respectively.

The ACI related to the CER was computed using the formulation from McCominsky and Feingold (2008):

$\mathrm{ACI}=-\left.\frac{\partial \ln \mathrm{CER}}{\partial \ln \alpha}\right|_{\mathrm{LWP}}$,

which indicates how a change in the CER depends on a change in the aerosol loading $\alpha$, given by either the AI or the AOD, for a constant LWP. The ACI was computed by dividing the CER and the AI-AOD over LWP bins ranging from 20 to $300 \mathrm{~g} \mathrm{~m}^{-2}$ with an interval of $40 \mathrm{~g} \mathrm{~m}^{-2}$ and then by performing a linear regression analysis with the logarithms of 


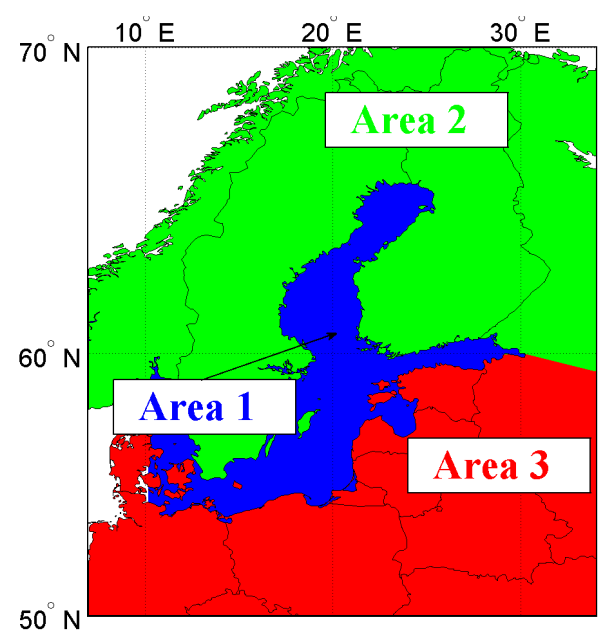

Figure 1. The area covered in this study and its division into three subregions: Area 1, the Baltic Sea, is represented by the colour blue; Area 2, covering the land areas of Fennoscandia, is represented by the colour green and Area 3, in red, includes the land areas of central-eastern Europe.

the CER and $\alpha$ in each LWP bin. Two approaches were applied to present the ACI: in the first, the ACI were obtained for each subregion and plotted as a function of the LWP, while in the second approach the ACI was computed in a $2^{\circ}$ spatial grid. In the grid approach we chose the LWP interval that provided statistically significant ACI estimates for each of the three subregions. The statistical significance is determined by the null hypothesis test scoring a $p$ value $<0.05$ (Fisher, 1958).

\section{Results}

Figure 2 presents the time series of $\mathrm{AI}$ and $\mathrm{AOD}$ averages during the summer months from 2003 to 2014 for each subregion. It is easy to see in Fig. 2 that these three areas have generally different aerosol conditions: within the land subregions, the lower AI and AOD averages occur over Area 2, while over Area 3 these values are higher during the entire period. Area 1, the Baltic Sea, is considered as a third subregion per se due to the dominance of maritime aerosol conditions. The AI is highest over Area 3 (central-eastern Europe), with an overall AI mean value of $0.29 \pm 0.03$ (regional mean \pm standard deviation), followed by Area 1 (Baltic Sea) with a mean value of $0.20 \pm 0.02$, while over Area 2 (Fennoscandia) the lowest AI mean value of $0.16 \pm 0.01$ is found. Area 3 also presents the highest averages for the AOD, $0.22 \pm 0.02$, but Area 2 and Area 1 have comparable AOD values: $0.16 \pm 0.02$ and $0.14 \pm 0.01$ respectively.

The spatial variations of the aerosol and cloud properties are shown in Fig. 3. A decreasing south-north gradient of AOD is observed in Fig. 3a where the highest val-

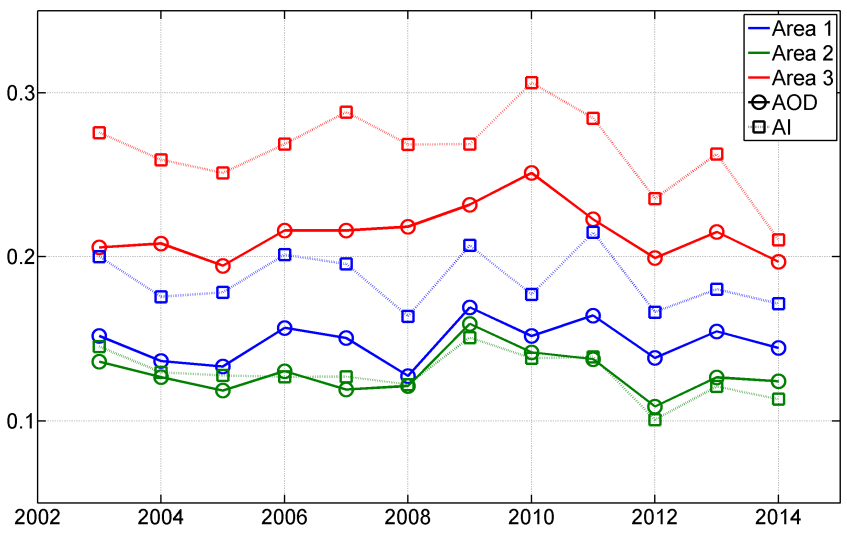

Figure 2. Time series of summer (JJA) averages for AOD (circles) and $\mathrm{AI}$ (squares) for the three subregions. The three subregions are colour-coded as in Fig. 1.

ues are found over Area 3 (northern Germany and Poland), and the lowest are found over Area 2 (the Atlantic coast of Norway and northern Sweden). While no discontinuities can be seen for the AOD distribution over Area 1 and Area 2, a clear distinction is evident in the AE (Fig. 3b). Indicating the dominance of fine particles, high values of the $\mathrm{AE}$ are found over the entire Area 1, over the eastern part of Area 3 and over the north-western part of Area 2. Low values $(\mathrm{AE}<1)$ are only partially found over the land of Areas 2 and 3. The validity of the MODIS AE over land is generally considered unrealistic. Nonetheless, in the case of the dominance of fine-mode aerosols, the MODIS AE agrees with AERONET (Levy et al., 2010), while disagreements occur in coarse aerosol cases (Jethva et al., 2007; Mielonen et al., 2011). Over ocean, a good agreement between MODIS $\mathrm{AE}$ and AERONET is found globally with the limitation of AOD > 0.2 (Levy et al., 2015), a restriction that cannot be applied in our study area where the regional AOD is about 0.2 . As the sensitivity of AE to AOD errors is especially critical for low AOD values, pixels with $\mathrm{AOD}<0.2$ are expected to have a less-qualitatively accurate AE. Nevertheless, the AE over Area 1 (Fig. 3b) matches the median range of 1.461.49 obtained from a validation study that compares the $\mathrm{AE}$ retrieved by SeaWiFS and MODIS Aqua or Terra with the three AERONET stations over the Baltic Sea (Melin et al., 2013). Comparable high AE values were collected by Rodriguez et al. (2012) from 2002 to 2011 at the subarctic ALOMAR Observatory (Andøya, Norway): the AE peaks during the summer season with a multi-annual mean and standard deviation of $1.3 \pm 0.4$. The AI (Fig. 3c) over Area 1 is comparable to the values over Area 3, while the lowest values occur over Area 2. The spatial distributions of the cloud properties (COT, CER, CF) are shown in Fig. 3d-f. As in the aerosol case, Area 2 presents a distinctive discontinuity between land and water pixels (Fig. 3d-f). These results are confirmed in Karlsson (2003), where Area 1 (the Baltic 

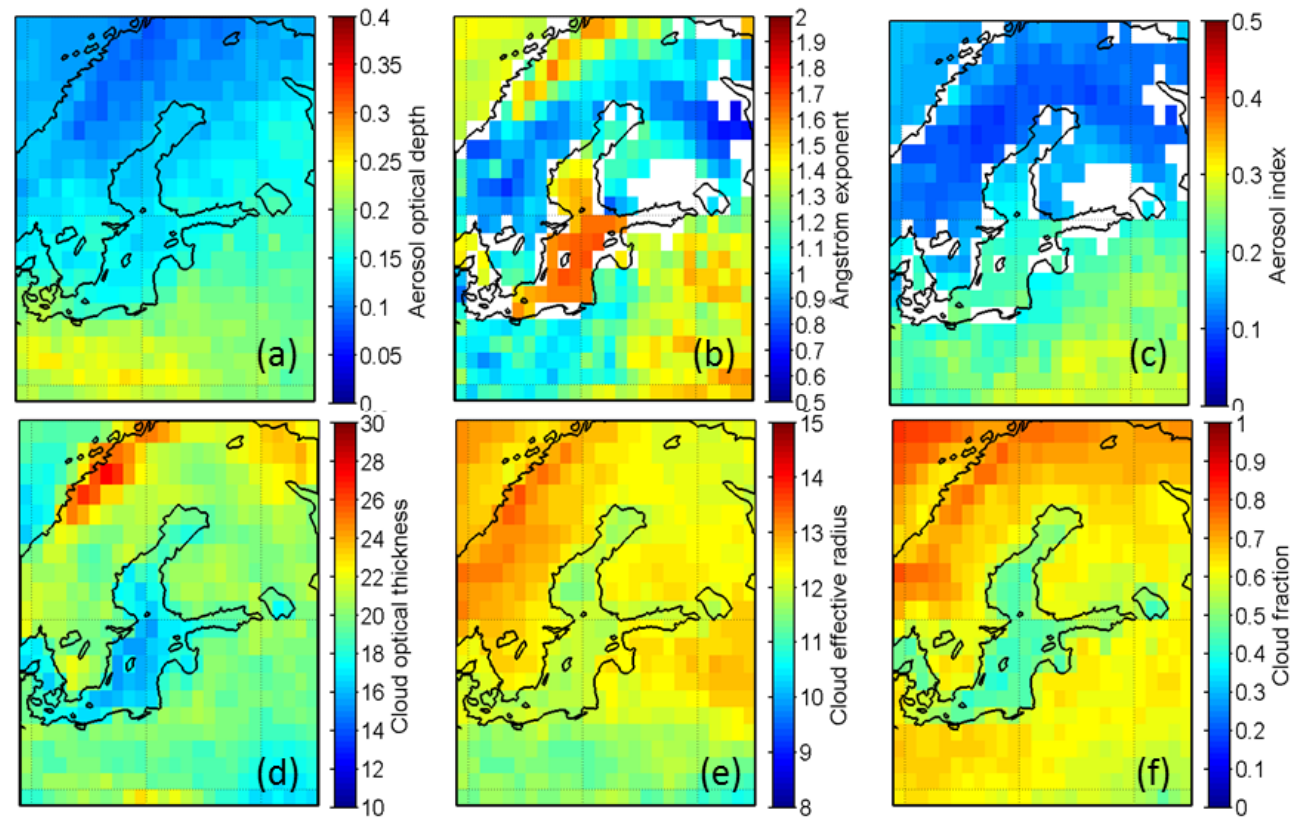

Figure 3. Spatial distributions of AOD (a), AE (b), AI (c), COT (d), CER (e) and CF (f) averages for summer seasons between 2003 and 2014.

Sea) exhibits low cloudiness while high cloud amounts are found over the Scandinavian mountain range (Area 2) and the Norwegian Sea. Considering the theory of the first AIE, that is, an increase in aerosol loading leads to larger CDNC and smaller CER for a fixed LWP, the CER (Fig. 3e) shows correlation with the AOD spatial distribution (Fig. 3a), while the worst comparison is found between CER (Fig. 3e) and AI (Fig. 3c). Over the Norwegian coast the high values of COT, CER and the CF can be explained by high hygroscopicity of sea spray aerosols, which makes these particles very efficient $\mathrm{CCN}$. Another feature of Fig. 3e is the low effective droplet radius over Area 1 (the Baltic Sea). Unlike Area 3 (centraleastern Europe), Area 1 does not match with any high aerosol loading (Fig. 3a, c) when compared to the surrounding area. In fact, the AOD over Area 1 is as low as in Area 2 (Fig. 2), even though the CER is about $1-2 \mu \mathrm{m}$ larger for these land areas.

Figure 4 presents the 10-year average of the cloud properties, divided into five classes of the AI (Fig. 4a-d) and AOD (Fig. $4 \mathrm{e}-\mathrm{h}$ ) plotted as a function of cloud-top pressure. It can be observed that the lowest values of CTP correspond to the higher classes of AI-AOD. Assuming the CTP to be an indicator of the cloud-top height, this may suggest an enhancement of the cloud vertical structure. This result was also found by Koren et al. (2005), where convective clouds over the North Atlantic showed a strong correlation between the aerosol loading and the vertical development of the clouds. Furthermore, the cloud droplet effective radius (Fig. 4a, e) has smaller values in higher AI-AOD classes. The opposite behaviour, lower average values corresponding to the lower classes of the AI-AOD can be seen for the COT (Fig. 4c, g) and LWP (Fig. 4d, h), while the CF (Fig. 4b, f) shows a weaker signal for both AI and AOD cases. Overall, Fig. 4 reveals that the cloud parameters are clearly affected by the AI-AOD segregation at lower levels of CTP. For this reason, we limit our data set to cloudy pixels where the CTP is between 700 and $900 \mathrm{hPa}$.

In Fig. 5 the CER is plotted as a function of AI for fixed values of the LWP (five intervals as above) and the CTP (between 700 and $950 \mathrm{hPa}$, in $50 \mathrm{hPa}$ bins). The highest $\mathrm{AI}$ in Area 1 (the Baltic Sea) is around 0.35 for the lowest clouds (CTP 900-950 hPa), decreasing to 0.3 for the highest clouds (CTP 700-750 hPa). Over Area 2 (Fennoscandia) the aerosol loading is not clearly connected to the cloud height, showing a constant AI average of approximately 0.25 . As expected, Area 3 has the highest average of AI out of the three subregions, with values as high as 0.6 for the lowest clouds and a small decrement for the highest clouds. The cloud droplet size in Area 1 (the Baltic Sea) and Area 2 (Fennoscandia) shows a strong negative correlation with the AI, while a weak correlation is observed over Area 3 (central-eastern Europe). Area 1 has no results for the high LWP bins: during summer months few or no convective clouds form over the Baltic Sea and mainly thin stratiform clouds are identified in the cloud cover. Similar results are also found when the AOD is substituted by the AI (not shown).

Applying Eq. (2) to the cloud parameters, the impact of low and high aerosol loading ( $\triangle$ Cloud_ $X$ ) on cloud properties (Cloud_ $X$ ) is presented in Fig. 6. Resulting from a gridbased analysis, $\Delta$ Cloud_ $X<0$ means that the observed cloud 

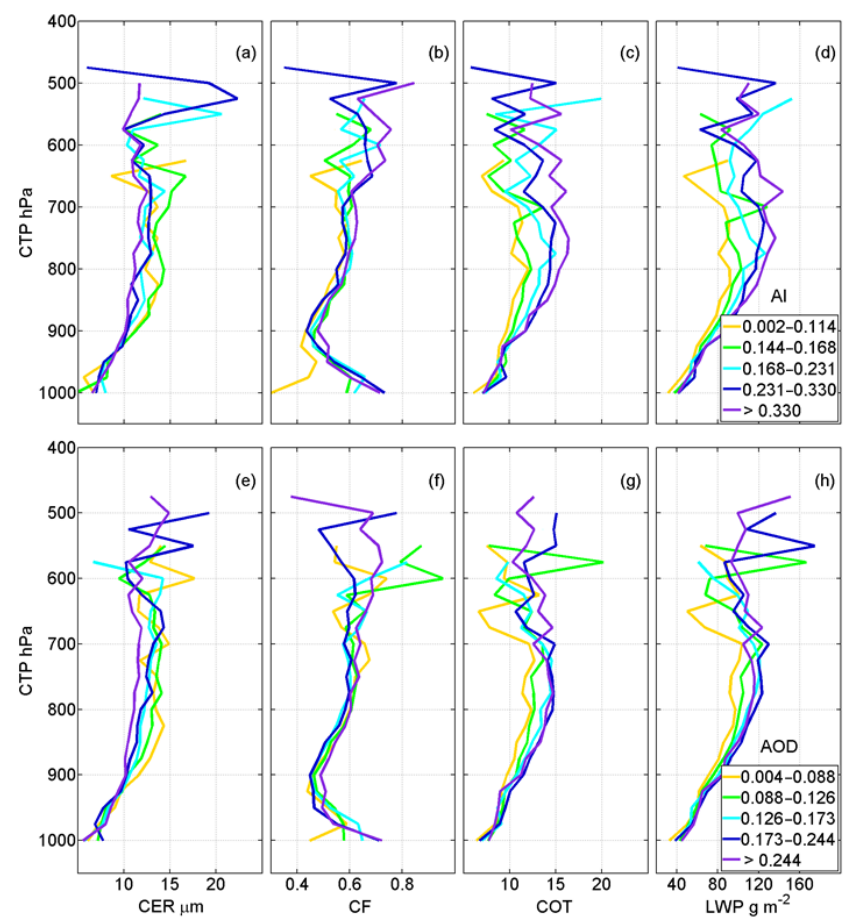

Figure 4. Cloud properties, 10-year averaged, as a function of cloud-top pressure: CER $(\mathbf{a}, \mathbf{e}), \operatorname{CF}(\mathbf{b}, \mathbf{f}), \operatorname{COT}(\mathbf{c}, \mathbf{g})$ and $\operatorname{LWP}(\mathbf{d}, \mathbf{h})$ as functions of cloud-top pressure (CTP) for five classes of AI (ad) and AOD (e-h). Each class of AI-AOD contains an equal number of samples in that interval.

parameter Cloud_ $X$ has a larger value in polluted cases (AIAOD $>75$ th percentile) than in clean atmospheric conditions $(\mathrm{AI}-\mathrm{AOD}<25$ th percentile) for that grid cell and vice versa when $\triangle$ Cloud_ $X$ has a positive value. As similar results were obtained by applying the AOD and AI, only the results for the AOD are shown. $\triangle \mathrm{CF}$ (Fig. 6a) presents only negative values, suggesting that the $\mathrm{CF}$ is always significantly larger in the polluted atmospheric conditions. The positive values of $\triangle \mathrm{CTP}$ (Fig. 6d) over Area 2 (Fennoscandia) and Area 3 (central-eastern Europe) agree with the idea of the vertical development of clouds for higher aerosol loadings (Fig. 4). However, other factors, such as surface heating, might also be contributing to the results: the presence of stronger turbulence over land cause the clouds to rise higher than in the presence of lower turbulence, for example, over a cooler water surface. The CER (Fig. 6c) shows a different behaviour over land (Area 3) than over water (Area 1). Over Area 3 $\triangle \mathrm{CER}$ is predominantly negative: although small $(<2 \mu \mathrm{m})$ negative values of the $\triangle \mathrm{CER}$ indicate that the CER is larger over areas with higher aerosol loadings than over cleaner areas. This result is in contradiction with the theory of the AIEs. The presence of aerosol appears to have little or no effect on $\triangle$ COT (Fig. 6b) and $\triangle$ LWP (Fig. 6e).

In an attempt to connect the link between aerosol and clouds with meteorology, we evaluated the variability of low- level liquid cloud properties as a function of aerosol conditions (AOD-AI) and lower troposphere stability (LTS). Figure 7 shows the cloud properties (LWP, CER, CF and COT) plotted as a function of the LTS and AI-AOD. While the CF shows a gradient for both directions of the LTS and the AI-AOD, the other cloud variables (LWP, CER, COT) are mainly affected by aerosols with little to no correlation with changes in the LTS. Higher aerosol values correspond to a smaller CER (Fig. 7b, f) and higher CF (Fig. 7c, g) and LWP (Fig. 7a), in agreement with the AIEs, except for the LWP (Fig. 7e), which decreases as a function of the AOD. The LWP (Fig. 7e) shows a non-monotonic response by increasing when the AOD ranges between 0.3 and 0.4 because at high aerosol concentrations the cloud droplets are smaller and less likely to precipitate, and furthermore the LWP slightly decreases. A possible explanation of a better correlation of the LWP with the AI than with AOD might be found by looking at the LWP vertical distributions in Fig. 4, which indicate a more distinctive separation of the LWP for the AI-based classes than for AOD.

Figure 8 illustrates the ACI estimate for the CER (Fig. 8a) and its corresponding correlation coefficient $r$ (Fig. 8b) calculated for the three subregions as a function of the LWP bins for both AOD and AI. The lines are colour-coded according to the three areas as defined in Fig. 1. The ACI estimates for Area 1 (Baltic Sea) are positive and statistically significant for most of the LWP range, increasing, as a function of LWP, from a minimum of 0.06 to a maximum of 0.16 and with a corresponding $r$ ranging from -0.1 to -0.53 . The values of the ACI for Area 2 range between 0.02 and 0.06, with fewer statistically significant points and a smaller $r$ than in Area 1. The results collected over both Area 1 and Area 2 appear to be little affected by whether the AOD or AI is applied in the computation of the ACI. For Area 3, two points of the ACI results are statistically significant but with very low values for correlations $(r<0.1)$ for the first two bins of the LWP and, unlike the other two subregions, they show a negative sign. The ACI values are statistically significant for the three subregions for the first two bins of LWP and when the AOD is chosen over the AI as $\alpha$. With a combination of these requirements, we derived the spatial distribution of the ACI and $r$, which are shown in Fig. 9. Positive correlations are found predominantly over Area 3 and scattered over Area 2, while negative values cover the majority of Area 1 and, more sparsely, Area 2. The relationship between CER and AOD is, paradoxically, positively correlated over Area 3, suggesting that high aerosol loading corresponds to larger cloud effective radius (Figs. 6c, 8, 9). One possible explanation might be the indication of the relationship between CTP and AOD: the CTP decreases for increasing AOD (Fig. 4), and at the same time the CER increases with decreasing CTP (higher altitude) in convective clouds (Rosenfeld and Lensky, 1998). Nonetheless, this result must be treated with care because other factors, such as hygroscopic effect, influence the rela- 


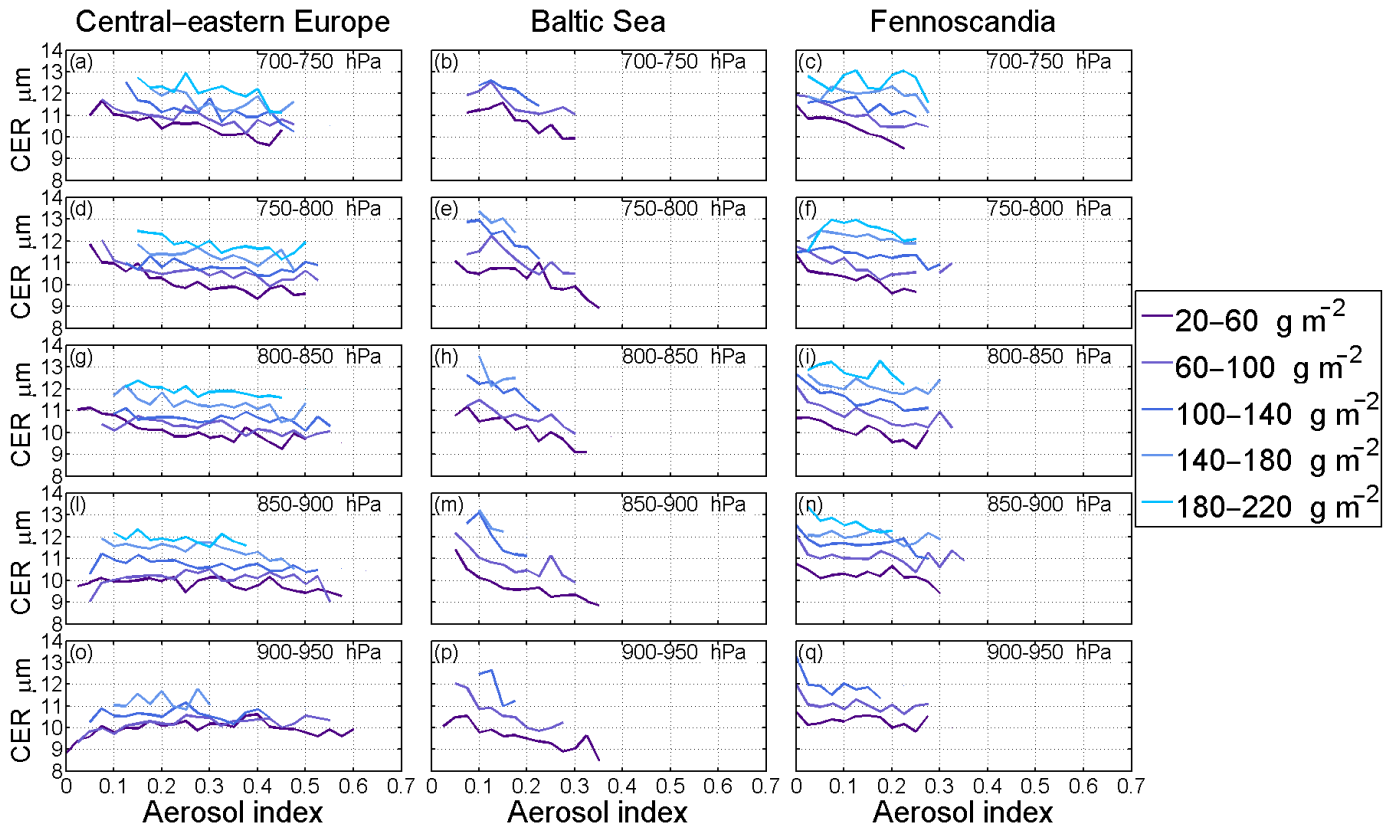

Figure 5. CER as a function of AI, stratified for subranges of CTP and LWP, for the three subregions. The legend on the right of the figure lists the LWP bins.
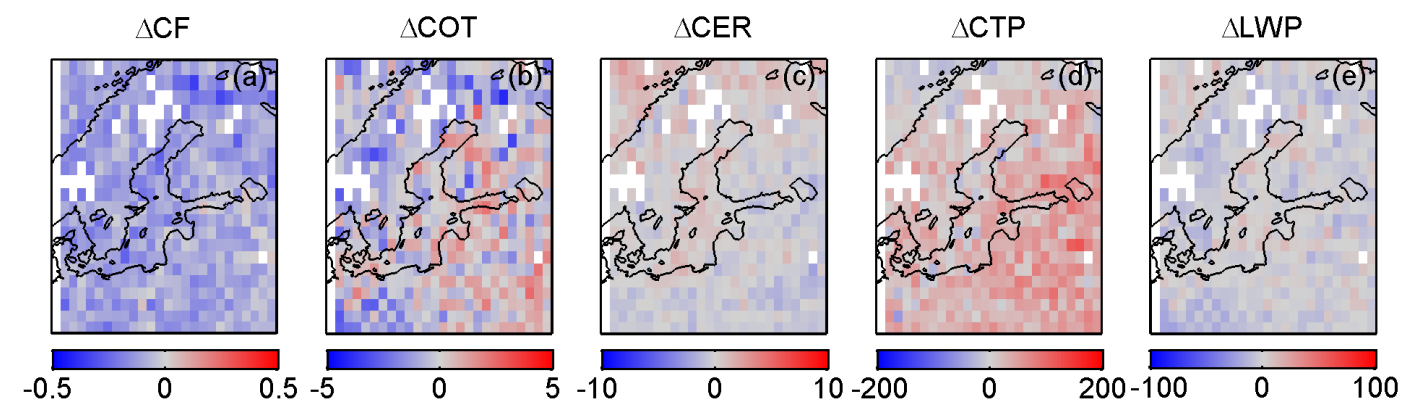

Figure 6. Spatial distributions of the difference of the cloud properties CF (a), COT (b), CER (c), CTP (d), and LWP (e) for low aerosol loading (AOD $<25$ th percentile) and heavy aerosol loading (AOD $>75$ th percentile) calculated from Eq. (2).

tionship between AOD and cloud parameters and cannot be fully ignored.

\section{Discussion and Conclusions}

In this work we have studied the applicability of satellitebased information for quantifying the ACI over the Baltic Sea region. Distinct subregional differences were found in the estimates of the ACI related to the effective radius of cloud droplets. No clear ACI results were observed for the other cloud parameters, which suggests that these may be influenced by other factors, such as the local meteorological conditions. The meteorological conditions are represented here by the LTS, which was compared to the cloud parameters. The LTS is correlated with the CF, while no effect was observed upon the other cloud parameters. In particular, there is no clear evidence of the effect of LTS on the interaction between aerosols and cloud effective radius.

One of the key aspects of this study was to find out whether a rigorously filtered Level 3 MODIS data set can be applied for ACI studies at a regional level. As the northerly location of the region of interest here restrains the availability of the MODIS observations to the summer months (JJA), one of the challenges is the limited data coverage. Moreover, the selection of specific cloud regimes and the co-location of aerosol and cloud observations are additional essential key factors in building up a robust data set, which, however, further decreases the amount of data points available. As far as the authors know, no previous results on ACI from a satellite perspective are provided over this area.

This study shows that the different aerosol conditions characterizing the Baltic Sea countries have an impact on the ACI and this can be also observed on a regional scale. According 


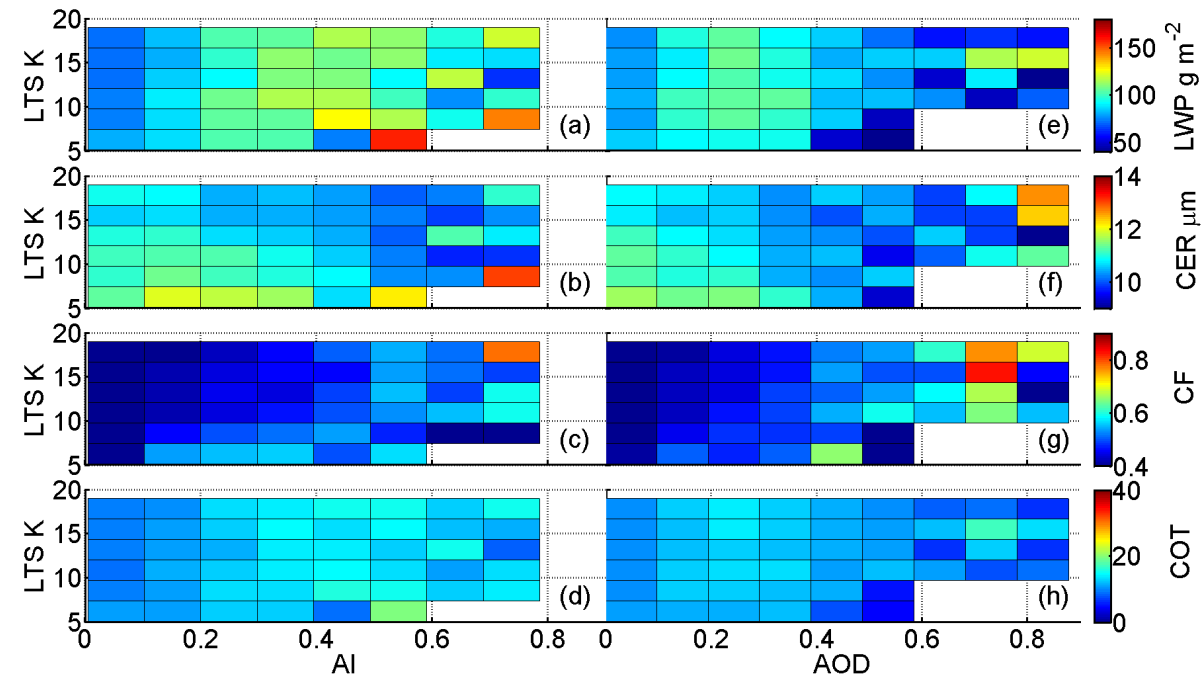

Figure 7. Mean low-level liquid cloud properties plotted as a function of LTS and AI (a-d) or AOD (e-h).
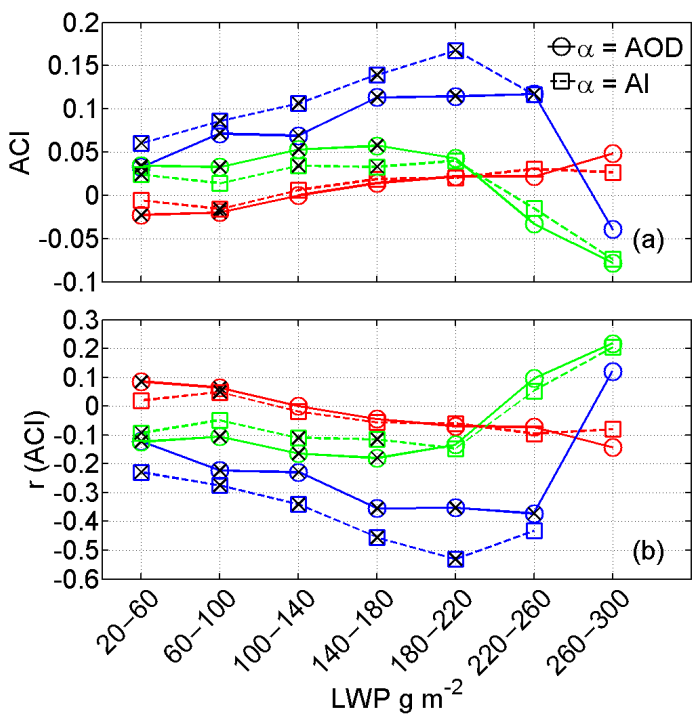

Figure 8. ACI estimates computed for the CER as a function of the LWP and by applying both the AI and AOD as proxies for the $\mathrm{CCN}$ are shown in (a). The correlation coefficients are presented in (b). The colour-coded lines refer to the three subregions determined in Fig. 1: Area 1 (blue), Area 2 (green) and Area 3 (red). The line styles define whether the AOD or AI were used as the CCN proxy, $\alpha$. Markers signed with a cross represent points fulfilling the null hypothesis ( $p$ value $<0.05)$, which are hence statistically significant.

to ACI theory, polluted atmospheric conditions are connected with clouds characterized by lower cloud-top pressure, larger coverage and optical thickness. However, the cloud effective radius strictly follows the AIE's theory only over Area 1 (the Baltic Sea), which also agrees with the results presented by Feingold (1997). As reported in this study, the CER retrieved

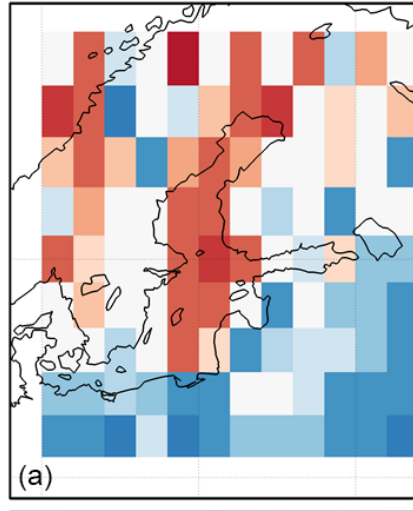

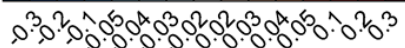

$A C l=-\partial(\log C E R) / \partial(\log A O D)$
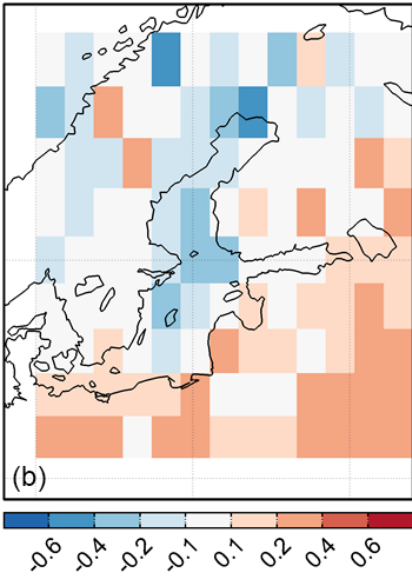

$r(\log (C E R), \log (A O D)$
Figure 9. Applying the AOD as a proxy for the $\mathrm{CCN}$, estimates of the ACI and correlation coefficient for the CER and for the interval of the LWP between 20 and $60 \mathrm{~g} \mathrm{~m}^{-2}$ were calculated on a grid basis. The obtained spatial distribution of the ACI is shown on the left and the correlation coefficient is shown on the right.

in clean clouds is mainly affected by the LWP and aerosol presence, while when detected under polluted conditions, it additionally shows a high dependence on other factors.

The cleaner atmosphere characterizing Area 1 (the Baltic Sea) and Area 2 (Fennoscandia) reveals statistically significant and positive ACI estimates between the CER and AOD that are in agreement with the values obtained from ground-based measurements collected at the sites of Pallas and Hyytiälä in Finland and Vavihill in Sweden (Lihavainen et al., 2010; Sporre et al., 2014b), while over the more polluted Area 3 (central-eastern Europe), the sensitivity to locally determine the ACI is smaller. It can be assumed that 
more aerosols lead to a high concentration of the CCN and this lowers the average droplet radius, as can be seen in Fig. 3e when the radius is compared between areas located south (high aerosol load) and north (low aerosol load) of the Baltic Sea.

Our analysis of the ACI for the CER shown in Fig. 8 leads to the following conclusions:

- The lowest values of the ACI can be seen over Area 3. This is also the subregion with the highest average AOD values, leading to the smallest cloud droplet size. A further addition of aerosol particles and thus possibly also $\mathrm{CCN}$ does not decrease the cloud droplet size any further. Most of the ACI values are actually negative but very close to zero.

- The positive ACI values for Area 2 show that the addition of aerosols to a relatively clean atmosphere does decrease the droplet size.

- The AI over the land areas in the study should be considered unrealistic because the average inland AE can have values below 1 .

- The average AE over Area 1 has values as high as 1.4 to 1.5. These values, however, can be trusted and have been evaluated by Melin et al. (2013).

- The low CER over Area 1 requires further explanation. The most probable cause for the low values, based on the MODIS cloud retrieval, is the relatively low cloudtop height over the sea. As cloud droplets generally grow in size from the cloud base towards the cloud top (McFiggans et al., 2006), Fig. 4 confirms that the average CER increases with the decreasing CTP. Furthermore, in Fig. 5 there is a distinctive lack of results for high LWP values, indicating that there are fewer clouds at higher top heights. These reasons altogether lead to low values of the CER over Area 1 since the MODIS instrument retrieves the droplet radius at cloud top, and the top height CER results are low when compared to the surrounding over-land values.

- The ACI over Area 1 has considerably higher values than over the land subregions, and there is a difference in the magnitude between the ACI values determined using the AOD or AI. The clean maritime atmospheric conditions lead to the high sensitivity of droplet size to changes in fine-particle concentrations. The AOD and AI difference in ACI, the latter being the higher, indicates that the ACI is caused by fine particles as expected.

Another way to assess the aerosol-induced changes in cloud parameters would be to analyse time series to find out whether dynamically decreasing or increasing aerosol loading has an effect on clouds. This sort of approach was not attempted in this work.
Another important result of this work is the comparison of the ACIs obtained using the AI and AOD, chosen as proxies for the $\mathrm{CCN}$, in order to determine which option leads to more realistic results. Even though theoretically the AI would be a better parameter than AOD to indicate the presence of fine-mode aerosol particles, the impact of uncertainties of the derived AI might be substantial.

\section{Data availability}

All data used in this study are publicly available. The satellite data from the MODIS instrument used in this study were obtained from https://ladsweb.nascom. nasa.gov/search/ (Saponaro, 2015a). The ECMWF ERAInterim data were collected from the ECMWF data server http://www.ecmwf.int/en/research/climate-reanalysis/ browse-reanalysis-datasets (Saponaro, 2015b).

Competing interests. The authors declare that they have no conflict of interest.

Acknowledgements. This research was funded by the Maj and Tor Nessling Foundation (grant no. 201600287). The authors also acknowledge the Academy of Finland Centre of Excellence (grant no. 272041).

Edited by: F. Yu

Reviewed by: two anonymous referees

\section{References}

Albrecht, B. A: Aerosols, cloud microphysics, and fractional cloudiness, Science, 245, 1227-1230, 1989.

Anderson, T. L., Charlson, R. J., Winker, D. M., Ogren, J. A., and Holmen, K.: Mesoscale variations of tropospheric aerosols, J. Atmos. Sci., 60, 119-136, doi:10.1175/15200469(2003)060<0119:MVOTA >2.0.CO;2, 2003.

Avey, L., Garrett, T. J., and Stohl, A.: Evaluation of the aerosol indirect effect using satellite, tracer transport model, and aircraft data from the International Consortium for Atmospheric Research on Transport and Transformation, J. Geophys. Res., 112, 21562202, doi:10.1029/2006JD007581, 2007.

Boucher, O., Randall D., Artaxo, P., Bretherton, C., Feingold, G., Forster, P., Kerminen, V.-M., Kondo, Y., Liao, H., Lohmann, U., Rasch, P., Satheesh, S. K., Sherwood, S., Stevens, B., and Zhang, X. Y.: Clouds and Aerosols, in: Climate Change 2013: The Physical Science Basis. Contribution of Working Group I to the Fifth Assessment Report of the Intergovernmental Panel on Climate Change, edited by: Stocker, T. F., Qin, D., Plattner, G.-K., Tignor, M., Allen, S. K., Boschung, J., Nauels, A., Xia, Y., Bex V., and Midgley P. M., Cambridge University Press, Cambridge, United Kingdom and New York, NY, USA, 571-657, 2013. 
Bréon, F.-M., Tanré, D., and Generoso, S.: Aerosol effect on cloud droplet size monitored by satellite, Science, 295, 834-838, L11801, doi:10.1126/science.1066434, 2002.

Costantino, L. and Bréon, F.-M.: Analysis of aerosol-cloud interaction from multi-sensor satellite observations, Geophys. Res. Lett., 37, L11801, doi:10.1029/2009GL041828, 2010.

Feingold, G.: Modeling of the first indirect effect: Analysis of measurements requirements, Geophys. Res. Lett., 30, 1-4, doi:10.1029/2003GL017967, 1997.

Fisher, R.: Statistical methods for research workers, Hafner, New York, 1958.

Grandey, B. S. and Stier, P.: A critical look at spatial scale choices in satellite-based aerosol indirect effect studies, Atmos. Chem. Phys., 10, 11459-11470, doi:10.5194/acp-10-11459-2010, 2010.

Jethva, H., Satheesh, S. K., and Srinivasan, J.: Assessment of second-generation MODIS aerosol retrieval (Collection 005) at Kanpur, India, Geophys. Res. Lett., 34, 1944-8007, doi:10.1029/2007GL029647, 2007.

Jones, T. A., Christopher, S. A., and Quaas, J.: A six year satellitebased assessment of the regional variations in aerosol indirect effects, Atmos. Chem. Phys., 9, 4091-4114, doi:10.5194/acp-94091-2009, 2009.

Karlsson, K.-G.: A 10 year cloud climatology over scandinavia derived from NOAA advanced very high resolution radiometer imagery, Int. J. Climatol., 23, 1023-1044, doi:10.1002/joc.916, 2003.

Klein, S. A. and Hartmann, D. L.: The seasonal cycle of low stratiform clouds, J. Climate, 6, 1587-1606, doi:10.1175/15200442(1993)006<1587:TSCOLS>2.0.CO;2, 1993.

Koren, I., Kaufman, Y. J., Rosenfeld, D., Remer, L. A., and Rudich, Y.: Aerosol invigoration and restructuring of Atlantic convective clouds, Geophys. Res. Lett., 32, L14828, doi:10.1029/2005GL023187, 2005.

Levy, R. C., Remer, L. A., Kleidman, R. G., Mattoo, S., Ichoku, C., Kahn, R., and Eck, T. F.: Global evaluation of the Collection 5 MODIS dark-target aerosol products over land, Atmos. Chem. Phys., 10, 10399-10420, doi:10.5194/acp-10-10399-2010, 2010.

Levy, R. C., Mattoo, S., Munchak, L. A., Remer, L. A., Sayer, A. M., Patadia, F., and Hsu, N. C.: The Collection 6 MODIS aerosol products over land and ocean, Atmos. Meas. Tech., 6, 29893034, doi:10.5194/amt-6-2989-2013, 2013.

Levy, R. C., Munchak, L. A., Mattoo, S., Patadia, F., Remer, L. A., and Holz, R. E.: Towards a long-term global aerosol optical depth record: applying a consistent aerosol retrieval algorithm to MODIS and VIIRS-observed reflectance, Atmos. Meas. Tech., 8, 4083-4110, doi:10.5194/amt-8-4083-2015, 2015.

Lihavainen, H., Kerminen, V.-M., and Remer, L. A.: Aerosol-cloud interaction determined by both in situ and satellite data over a northern high-latitude site, Atmos. Chem. Phys., 10, 1098710995, doi:10.5194/acp-10-10987-2010, 2010.

Matsui, T., Masunaga, H., Kreidenweis, S. M., Pielke, R. A., Tao, W.-K., Chin, M., and Kaufman, Y. J.: Satellite-based assessment of marine low cloud variability associated with aerosol, atmospheric stability, and dyurnal cycle, J. Geophys. Res., 111, D17204, doi:10.1029/2005JD006097, 2006.

McCominsky, A. and Feingold, G.: Quantifying error in the radiative forcing of the first aerosol effect, Geophys. Res. Lett., 35, L02810, doi:10.1029/2007GL032667, 2008.
McFiggans, G., Artaxo, P., Baltensperger, U., Coe, H., Facchini, M. C., Feingold, G., Fuzzi, S., Gysel, M., Laaksonen, A., Lohmann, U., Mentel, T. F., Murphy, D. M., O’Dowd, C. D., Snider, J. R., and Weingartner, E.: The effect of physical and chemical aerosol properties on warm cloud droplet activation, Atmos. Chem. Phys., 6, 2593-2649, doi:10.5194/acp-6-2593-2006, 2006.

Melin, F., Zibordi, G., Carlund, T., Holben, B., and Stefan, S.: Validation of SeaWiFS and MODIS Aqua/Terra aerosol products in coastal regions of European marginal seas, Oceanologia, 55, 2751, doi:10.5697/oc.55-1.027, 2013.

Mielonen, T., Levy, R. C., Aaltonen, V., Komppula, M., de Leeuw, G., Huttunen, J., Lihavainen, H., Kolmonen, P., Lehtinen, K. E. J., and Arola, A.: Evaluating the assumptions of surface reflectance and aerosol type selection within the MODIS aerosol retrieval over land: the problem of dust type selection, Atmos. Meas. Tech., 4, 201-214, doi:10.5194/amt-4-201-2011, 2011.

Myhre, G., Stordal, F., Johnsrud, M., Kaufman, Y. J., Rosenfeld, D., Storelvmo, T., Kristjansson, J. E., Berntsen, T. K., Myhre, A., and Isaksen, I. S. A.: Aerosol-cloud interaction inferred from MODIS satellite data and global aerosol models, Atmos. Chem. Phys., 7, 3081-3101, doi:10.5194/acp-7-3081-2007, 2007.

Nakajima, T., Higurashi, A., Kawamoto, K., and Penner, J. E.: A possible correlation between satellite-derived cloud and aerosol microphysical parameters, Geophys. Res. Lett., 28, 1171-1174, 2001.

Ou, S., Liou, K., Hsu, N., and Tsay, S.: Satellite remote sensing of dust aerosol indirect effects on cloud formation over Eastern Asia, Int. J. Remote Sens., 33, 7257-7272, doi:10.1080/01431161.2012.700135, 2013.

Rodriguez, E., Toledano, C., Cachorro, V. E., Oritz, P., Stebel, K., Berjón, A., Blindheim, S., Gausa, M., and de Frutos, A. M.: Aerosol characterization at the sub-arctic site Andenes $\left(69^{\circ} \mathrm{N}\right.$, $\left.16^{\circ} \mathrm{E}\right)$, by the analysis of columnar optical properties, Q. J. Roy. Meteor. Soc., 138, 471-482, doi:10.1002/qj.921, 2012.

Rosenfeld, D. and Lensky, I. M.: Satellite-based insights into precipitation formation processes in continental and maritime convective clouds, B. Am. Meteorol. Soc., 79, 2457-2476, 1998.

Saponaro, G.: Finnish Meteorological Institute, MODIS Atmosphere L3 Daily Gridded Product, available at: https://ladsweb. nascom.nasa.gov/search/, last access: 15 July 2015a.

Saponaro, G.: Finnish Meteorological Institute, ERA-Interim reanalysis data set, available at: http://www.ecmwf.int/en/research/ climate-reanalysis/browse-reanalysis-datasets, last access: 28 September 2015b.

Sayer, A. M., Munchak, L. A., Hsu, N. C., Levy, R. C., Bettenhausen, C., and Jeong, M.-J.: MODIS Collection 6 aerosol products: Comparison between Aqua's e-Deep Blue, Dark Target, and "merged" data sets, and usage recommendations, J. Geophys. Res.-Atmos., 119, 13965-13989, doi:10.1002/2014JD022453, 2014.

Sekiguchi, M., Nakajima, T., Suzuki, K., Kawamoto, K., Higurashi, A., Rosenfeld, D., Sano, I., and Mukai, S.: A study of the direct and indirect effects of aerosols using global satellite data sets of aerosols and cloud parameters, J. Geophys. Res.-Atmos., 108, 4699, doi:10.1029/2002JD003359, 2003.

Sporre, M. K., Swietlicki, E., Glantz, P., and Kulmala, M.: A longterm satellite study of aerosol effects on convective clouds in Nordic background air, Atmos. Chem. Phys., 14, 2203-2217, doi:10.5194/acp-14-2203-2014, 2014a. 
Sporre, M. K., Swietlicki, E., Glantz, P., and Kulmala, M.: Aerosol indirect effects on continental low-level clouds over Sweden and Finland, Atmos. Chem. Phys., 14, 12167-12179, doi:10.5194/acp-14-12167-2014, 2014 b.

Tao, W.-K., Chen, J.-P., Zhanqing, L., Wang, C., and Zhang, C.: Impact of aerosols on convective clouds and precipitation, Rev. Geophys., 50, RG2001, doi:10.1029/2011RG000369, 2012.

Twomey, S.: Influence of pollution on the short-wave albedo of clouds, J. Atmos. Sci., 34, 1149-1152, 1977.
Zhang, Z., Ackerman, A. S., Feingold, G., Platnick, S., Pincus, R., and Xue, H.: Effects of cloud horizontal inhomogeneity and drizzle on remote sensing of cloud droplet effective radius: Case studies based on large-eddy simulations, J. Geophys. Res., 117, D19208, doi:10.1029/2012JD017655, 2012. 